Article

\title{
Effective Ecological and Cheap Heating of Dwelling Spaces
}

\author{
Pavel Koštial ${ }^{1}$, Jozef Vlček ${ }^{1}$, Zora Koštialová Jančíková ${ }^{1}$, Hana Špačková ${ }^{2}$, Jiří David ${ }^{1}$, \\ Robert Frischer ${ }^{1}$ and Ivan Ružiak ${ }^{3, *(D)}$ \\ 1 Faculty of Materials Science and Technology, VŠB-Technical University Ostrava, 70800 Ostrava, Czech \\ Republic; pavel.kostial@vsb.cz (P.K.); jozef.vlcek@vsb.cz (J.V.); zora.kostialova.jancikova@vsb.cz (Z.K.J.); \\ j.david@vsb.cz (J.D.); robert.frischer@vsb.cz (R.F.) \\ 2 ITeuro, a.s., Hollarova 1124/14, 70200 Ostrava, Czech Republic; spackova@iteuro.cz \\ 3 Faculty of Wood Sciences and Technology, Technical University in Zvolen, 96001 Zvolen, Slovakia \\ * Correspondence: ruziak@tuzvo.sk;
}

Received: 29 October 2019; Accepted: 17 December 2019; Published: 19 December 2019

\begin{abstract}
The sustainability of human civilization depends largely on green energy management. This work represents one way to achieve this goal. The work is devoted to converting microwave radiation to heat. The article analyses different ways of heating residential and utility areas. Materials suitable for converting microwave radiation to heat from ceramic composites, concretes, fire clays, and bauxite with water glass are enclosed. For all materials we have measured DTA/TG (Differential Thermal Analysis/Thermogravimetric Analysis) curves, XRD (X-Ray Diffraction) patterns, chemical composition of samples, the specific heat capacity $c_{p}[J / k g . K]$, thermal conductivity $k$ $[\mathrm{W} / \mathrm{m} . \mathrm{K}]$ and diffusivity $\alpha\left[\mathrm{m}^{2} / \mathrm{s}^{-1}\right]$. The cooling curves of these materials after microwave heating are characterized in detail. The paper also presents a description and construction of a microwave reactor together with the parameters of the living space heating.
\end{abstract}

Keywords: Ceramic materials; microwaves; heating; energy conversion

\section{Introduction}

Energy consumption for heating in a family house currently accounts for about $70 \%$ of the total consumption. In an effort to reduce this consumption, the European Union provides various subsidies for green energy. The heating system is to ensure thermal comfort for the owners of the house. There are many ways of heating, i.e., traditional heating such as central heating, electric heating, heat pump, or infrared floor heating [1-13]. The annual consumption figures for each type of house are reported as follows: energy-efficient house $50-70 \mathrm{kWh} . \mathrm{m}^{-2}$, low-energy house $15-50 \mathrm{kWh} . \mathrm{m}^{-2}$, energy passive house $5-15 \mathrm{kWh} \cdot \mathrm{m}^{-2}$, zero house $0-5 \mathrm{kWh} \cdot \mathrm{m}^{-2}$ per year [1]. For a low-energy and passive house, the Blower door test, which characterize the air-tightness of building envelope [14], is very important. For energy-efficient houses, it is most important to ensure the lowest possible heat loss. Due to this fact, it is very important to measure thermophysical properties of wooden materials, which are the main parts of a wooden building envelope and which directly affect heat losses through the building envelope, which the authors measured in [15]. The shape of the house also affects energy consumption by two factors. The first factor is the necessity to achieve the smallest object surface possible for a given volume and the second factor is the reduction of potential thermal bridges. These two considerations result in the ideal shape of a ball, respectively a hemisphere [1].

The modern era favours mainly ecological and renewable sources, whether thermal or electricity. We also look at the comfort and regulation and, last not least, initial investments. Exogenous sources are sources such as solar, wind, hydropower, biomass and wave energy, thermal energy of the seas 
and oceans or the environment. The most suitable sources of this origin for heating modern homes are solar energy and energy from biomass. Wind energy is less advantageous; it can rather attract enthusiasts but its potential for family houses is not so great simply because such types need an open environment exposed to appropriate weather conditions. However, as mentioned, placing an object in such an environment increases the heat loss. The solution would be expensive and complicated, which would not pay off. Solar energy, on the other hand, is useable with a good potential in almost every family house or industry. The solar radiation after the impact on the surface area creates values from 1000 to $1250 \mathrm{kWh}$ per year, thus using a photovoltaic panel or solar collectors can heat a household. Photovoltaic panels in the form of a sunroof have also entered the market, making use of two functions. There are also various collectors-window or wall. The window collector has a thickness of 20 to $30 \mathrm{~cm}$ and corresponds to a double window. Heat accumulated in the cavity is then consequently transferred to the storage tank by gravity or by a fan.

Radiation heat has already been used for many centuries. A typical conventional heat is supplied, for instance, by a radiator or a typical electric heater (convector), through heating the air in its neighbourhood. At their surface temperature of $90^{\circ} \mathrm{C}$, infrared panel heaters radiate at the wavelength of approximately 9 to $10 \mu \mathrm{m}$, which is a suitable component for the human organism, influencing the growth of organism cells and psychological comfort.

Microwave electromagnetic radiation represents another very efficient method of radiation heating. As opposed to other heating methods, higher temperatures can be achieved by a dielectric heating inside the heating body instead of on its surface [16-18].

This paper contains an experimental analysis of the physical aspects of the conversion of microwaves to heat, while ensuring the safety of such a process. Specific ceramic materials were selected and experimentally checked for such a conversion. The functionality and economic aspects of this process are also verified in a special converter developed for this purpose.

\section{Theoretical Part}

This section describes the generation of heat by penetration of microwaves into the solid material. The electric alternating field affects the population of particles forming a dielectric medium, which moves steadily due to thermal motion.

Dielectric specific losses $Q$ will be determined according to the following relation [19]:

$$
Q=0.5 \varepsilon_{0} \varepsilon^{\prime} \operatorname{tg} \delta \omega E^{2}
$$

where

E is the electric field intensity,

$\varepsilon^{\prime}=\varepsilon_{\mathrm{r}}$ is the relative permittivity,

$\varepsilon^{\prime \prime}=\varepsilon_{\mathrm{r}} \operatorname{tg} \delta$ is the loss number,

$\varepsilon_{0}$ is the vacuum permittivity,

$\omega$ is the angular frequency of electric field,

$\operatorname{tg} \delta$ is the loss factor.

This derived formula takes into consideration the losses conditioned by polarisation effects. In real dielectric media, which are always characterised by a certain value of conductivity, the conductive component contributes to the losses of electric current passing through the dielectric medium. The current density can be expressed in accordance with Ohm's Law in the form:

$$
J=\gamma \cdot \mathrm{E}
$$

and the specific losses $Q_{\mathrm{ec}}$ by the formula:

$$
Q_{e c}=\gamma \cdot E^{2}
$$


where

$\mathrm{J}$ is the current density vector,

$\gamma$ is the specific conductivity.

If compared with (2), the following result obtains:

$$
\operatorname{tg} \delta=\frac{\gamma}{\omega \varepsilon_{0} \varepsilon^{\prime}} ; \varepsilon^{\prime \prime}=\frac{\gamma}{\omega \varepsilon_{0}} .
$$

The specific dielectric losses are not only the function of the loss factor $\operatorname{tg} \delta$, but other variables also come into play. With increasing $\omega$ or $E$, the quality requirements for the dielectric medium always rises as well, usually to a low value of $\operatorname{tg} \delta$. Thus, due to the low dielectric losses, the question of the relative permittivity level can be disregarded as well [19].

According to previous analyses the dominant role in the heat development in a real dielectric sample at microwave frequencies is played by dipoles and ions.

\section{Experimental Conditions}

With reference to previous theoretical assumptions, we will now try to specify materials suitable for the efficient transformation of microwaves into heat, because we cannot let the microwaves themselves be emitted into the living space because of their harmful effect (high energy) on the human body. As we will see, metallurgical ceramics appear to be prospective materials for these purposes.

We generally define ceramics as an inorganic nonmetallic mass characterised by a heterogeneous structure consisting generally of a crystalline phase, a glass phase, and pores. The basic composition of the ceramic mass consists of unprocessed plastic (kaolin, clays_enabling the shaping of masses, which usually contain water but also ions) and non-plastic raw materials. These are both fluxes-during firing they help to form melt and grit-in terms of production technology and they affect the shrinkage and malleability of the plastic mixture and are the main part of the material. However, such materials must also have suitable mechanical properties (strength, hardness), which are influenced by their structure.

Depending on the type of binder used, different physical/chemical processes take place when the material is hardened. The bond in the material is formed by different processes at different temperatures.

A ceramic bond consists of clays. For some specific hardening processes of the material, using clay as a binder takes place after drying. The loss of chemically bound water occurs in the temperature range of 450 to $600{ }^{\circ} \mathrm{C}$.

Hydraulic bonding is formed by the reaction of cement with water at a normal temperature. Two basic types of cement are used-Portland and aluminous. The mixtures of refractory aggregate and cement are refractory concrete. These minerals hydrate when in contact with water. Hydrates with different water contents cause the hardening of the material. During heating, water is released again and strength is reduced. Only at high temperatures does a direct ceramic bond (mineral grain growth, sintering) occur.

A chemical bond is formed, e.g., using phosphorus binders, water glass, magnesium chloride or sulphate and other substances. Firming and hardening occur through a chemical reaction.

The phosphorous bond is formed by phosphoric acid or ammonium, sodium or potassium phosphates (however, alkali oxides reduce the heat resistance). It is used in mixtures with aluminosilicate aggregates. The chemical reaction with the aggregate produces aluminium phosphates. Heating causes dehydration and polyphosphates.

Water glass consists of sodium or potassium silicates which are soluble in water or mixtures thereof. As a binder, water glass is used in non-shaped materials, such as in lean clay, e.g., fire clay or sand.

Organic binding is mainly used for basic materials. The binder is tar, sulphite liquor, carboxymethylcellulose, polyvinyl alcohol and others. These binders are applied as a bond only up to 
the decomposition and burn-out temperatures, i.e., up to about $200^{\circ} \mathrm{C}$. A carbon-based bond is formed in the reducing atmosphere.

Hydraulic binders are substances which, under the effect of water, produce products which, upon initial air-curing, further solidify and harden both in air and in water, the resulting products being insoluble in water. Latent hydraulic substances are those which exhibit their hydraulicity under the influence of a suitable activator. They are inert or react very slowly to the action of the water itself and the strength parameters achieved by bodies prepared from them are insufficient.

An interesting alternative to hydraulic binders are the so-called latent hydraulic substances. They show their hydraulicity under the effect of a suitable activator.

There are many latent hydraulic materials in nature. They are also referred to as pozzolans. The term pozzolan originates from the name of the Italian town of Pozzuoli, where there were products of volcanic activity (showing latent hydraulicity), which were used before the common era to construct the first concrete constructions. In order to be classified as a pozzolan, the material must, when finely ground, react with calcium hydroxide at room temperature to form new phases that solidify and harden. Water (in varying amounts) is also needed to stimulate the latency of the latent hydraulic fluids, which allow the formation of hydration products or the distribution of the activator. The addition of water during alkaline activation may be partially or completely replaced by an activator if it is in the form of an aqueous solution.

In addition to natural pozzolans, there are also artificial pozzolans. Both are materials with a high content of active $\mathrm{SiO}_{2}$ oxides and $\mathrm{Al}_{2} \mathrm{O}_{3}$. The above substances, both natural and artificial, meet certain conditions that guarantee their latent hydraulicity. First, it is their composition. According to literature [20-22], pozzolans usually contain more than $70 \%$ of the two principal oxides. $\mathrm{CaO}$ is another essential oxide for the assessment of hydraulics. Its content depends on the type of hydration products, and the form in which it is present is decisive in whether the substance is latent hydraulic or hydraulic. The accompanying components of latent hydraulic substances are oxides $\mathrm{Fe}_{2} \mathrm{O}_{3}, \mathrm{MgO}$, $\mathrm{Na}_{2} \mathrm{O}, \mathrm{K}_{2} \mathrm{O}$, and others [4-7,12]. It can be stated that calcined clays are latent hydraulic if they contain thermally degraded, i.e., amorphous, phases. For example, in the case of kaolinite, this may not only be metakaolinite, but also amorphous $\mathrm{SiO}_{2}$, which forms at higher temperatures of heat treatment.

Fly ash is a waste product in the combustion of solid fuels. The main constituents of fly ash are $\mathrm{SiO}_{2}$, $\mathrm{Al}_{2} \mathrm{O}_{3}$, and $\mathrm{Fe}_{2} \mathrm{O}_{3}$. During the flue gas desulfurization process, the content of $\mathrm{CaO}$ and $\mathrm{MgO}$ increases.

Microsilica is the name of a waste product of the production and processing of silicon and silicon alloys at temperatures exceeding $2000^{\circ} \mathrm{C}$. The composition of microsilica depends on the technology with which it is formed and on the system and efficiency of the capture device. It contains up to $95 \%$ amorphous $\mathrm{SiO}_{2}$, the other ingredients being $\mathrm{Al}_{2} \mathrm{O}_{3}(0.1-0.5 \%), \mathrm{Fe}_{2} \mathrm{O}_{3}(2-5 \%)$, and tenths of a percent of $\mathrm{C}, \mathrm{S}, \mathrm{CaO}, \mathrm{TiO}_{2}$, and alkali.

There is also slag from non-ferrous metal production. These substances may also exhibit latent hydraulicity. This has been proven in slag from nickel, copper, lead, and zinc production.

One of the most commonly applied alkaline activators is water glass. It may be in the form of a colloidal solution of alkali silicates (most often sodium, less frequently potassium) or in the form of solid hydrated and non-hydrated alkali silicate.

The list of potentially interesting materials ends with geopolymers. A geopolymer is a substance that is formed by inorganic polycondensation, geopolymerisation, as a consequence of the alkaline activation of alumosilicate substances [23]. The basic types of geopolymers consist of alternating $\mathrm{SiO}_{4}$ and $\mathrm{AlO}_{4}$ tetrahedra.

Two-dimensional structures belong among such materials in the first place, such as clays [20-22]. Clay minerals with a layered structure have often been used as matrices for such type of organo-inorganic composites. Interaction of guest species with negatively charged structure can offer new applications of these composites $[4-7,22]$.

The application of different physical and chemical treatments at the purification of waste materials is described in [24-26]. 
Now, let us pay attention to the properties of potential materials usable for microwave heating. According to the analysis shown above, they should particularly contain water ions and dipoles.

The amount of heat that the material is able to absorb is mainly indicated by the heat capacity of the material, which is influenced by the material density. For ceramic materials, its total volume is given by the sum of the volumes contained in the phases. These form solid phases and pores. The density is the ratio of the weight of dry material to its actual volume, that is to say the volume of only the solid phase without pores.

Together, the heat capacity and bulk density affect the amount of heat accumulated in each material, but they do not provide information on the rate of heat output. Therefore, a diffusivity value $\alpha\left[\mathrm{m}^{2} . \mathrm{s}^{-1}\right]$ is used to provide information on the rate of heat propagation through the material.

\section{Results}

In this section, we will look at the ability of the materials described above to participate in the effective conversion of microwave radiation to heat.

The material was processed into the form of small bricks, with dimensions of $4 \times 1.5 \times 16 \mathrm{~cm}^{3}$ (fire clay) or castings and bauxite with dimensions of $4 \times 4 \times 16 \mathrm{~cm}^{3}$. The small bricks were heated for ten minutes in a microwave oven at its full output $(1200 \mathrm{~W})$ and a frequency of $2.45 \mathrm{GHz}$. The cooling of the sample was measured by a thermocouple in the microwave oven (closed and switched off). The cooling curves of the bricks with pressed-in metal netting show the influence of induced high frequency currents in the metallic net on the temperature rise in the materials.

The chemical composition of the materials was determined by the XRFS (X-Ray Fluorescence Spectroscopy) method using a Rigaku Supermini 200 equipped with a Pd anode, and the measurement was performed in a non-standard measurement mode. The phase composition of the samples was determined by the XRD method using a Rigaku Miniflex instrument. The device is equipped with Co anode, linear $1 \mathrm{D}$ detector. The measurement was performed in the range of 5 to $1002 \theta$ with a goniometer feed rate of $5{ }^{\circ} \mathrm{C} \mathrm{min}-1$ and a goniometer feed rate of $0.01^{\circ}$. PDXL software and the PDF-2 ICDD mineralogical database were used for interpreting the measured phases. Thermal analysis was measured using an SDT 650 instrument from TA Instruments. The measurement took place in an uncontrolled atmosphere; the heating rate was $10 \mathrm{~K} \cdot \mathrm{min}^{-1}$. Ignition loss was determined in an oxidizing atmosphere at $1000{ }^{\circ} \mathrm{C}$.

To assess the suitability of a respective material, we will use the specific heat capacity, thermal conductivity and diffusivity as well as the density. These values were measured at room temperature by the LCM method described in [27].

Based on the facts described in the Section 3 we have selected three materials that, in our opinion, which is based on previous structural analysis, could be suitable for converting microwaves into heat. These are fire clay, refractory concrete, and a mixture of bauxite with water glass. Figures 1-3 show the surface structures of porous materials. Samples of fire clay and concrete were after its preparation heat treated in temperature $1100{ }^{\circ} \mathrm{C}$, the sample of bauxite in temperature $900{ }^{\circ} \mathrm{C}$.

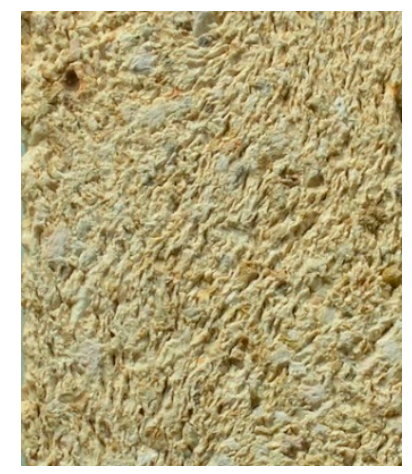

Figure 1. Fire clay. 


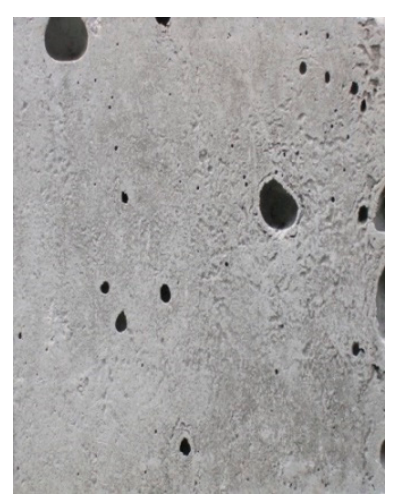

Figure 2. Refractory concrete.

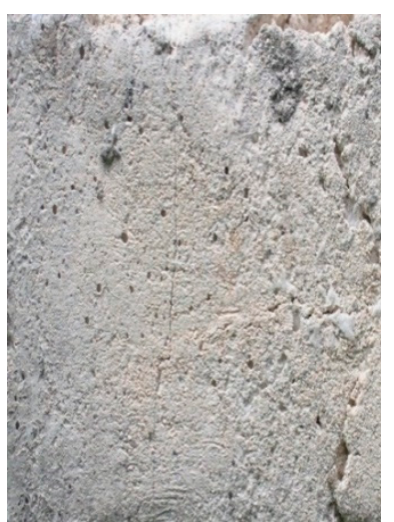

Figure 3. Bauxite with water glass.

Thermal data obtained by method described in [27] are presented in Table 1.

Table 1. Thermal parameters for materials under investigation.

\begin{tabular}{ccccc}
\hline Material & $\left.\mathbf{c}_{\mathbf{p}} \mathbf{~} \mathbf{J} / \mathbf{k g} . \mathbf{K}\right]$ & $\boldsymbol{\alpha}\left[\mathbf{m}^{\mathbf{2}} \mathbf{s}^{-\mathbf{1}}\right]$ & $\mathbf{k}[\mathbf{W} / \mathbf{m} . \mathbf{K}]$ & $\boldsymbol{\rho}\left[\mathbf{k g} / \mathbf{m}^{\mathbf{3}}\right]$ \\
\hline Fire clay & 890 & $7.9 \times 10^{-7}$ & 1.19 & 1700 \\
Concrete & 890 & $6.4 \times 10^{-7}$ & 1.30 & 2297 \\
Bauxite & 1000 & $8.2 \times 10^{-7}$ & 1.80 & 2200 \\
\hline
\end{tabular}

\subsection{Fire Clay}

The tested material was fire clay (squeezed) with a composition of $\mathrm{Al}_{2} \mathrm{O}_{3} \geq 36$. The pore content is $6.7 \%$. The chemical composition of the fire clay is shown in Table 2 and phase composition in Figure 4. Figure 5 represents fire clay DTA/TG curves.

Table 2. Chemical composition of fire clay sample.

\begin{tabular}{cccccccccccc}
\hline Component & $\mathrm{Al}_{2} \mathrm{O}_{3}$ & $\mathrm{SiO}_{2}$ & $\mathbf{P}_{2} \mathrm{O}_{5}$ & $\mathrm{Na}_{2} \mathrm{O}$ & $\mathrm{K}_{\mathbf{2}} \mathrm{O}$ & $\mathrm{CaO}$ & $\mathrm{TiO}_{2}$ & $\mathrm{Cr}_{2} \mathrm{O}_{3}$ & $\mathbf{M n O}_{2}$ & $\mathrm{Fe}_{2} \mathrm{O}_{3}$ & $\mathrm{LOI}$ \\
\hline Result (wt\%) & 44.8 & 42.7 & 0.74 & 1.05 & 1.60 & 0.87 & 3.73 & 0.19 & 0.13 & 4.5 & 0.69 \\
\hline
\end{tabular}




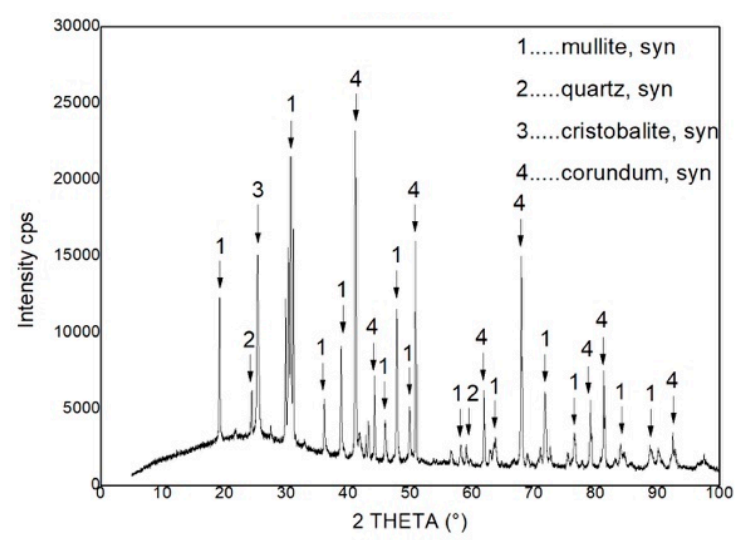

Figure 4. XRD pattern.

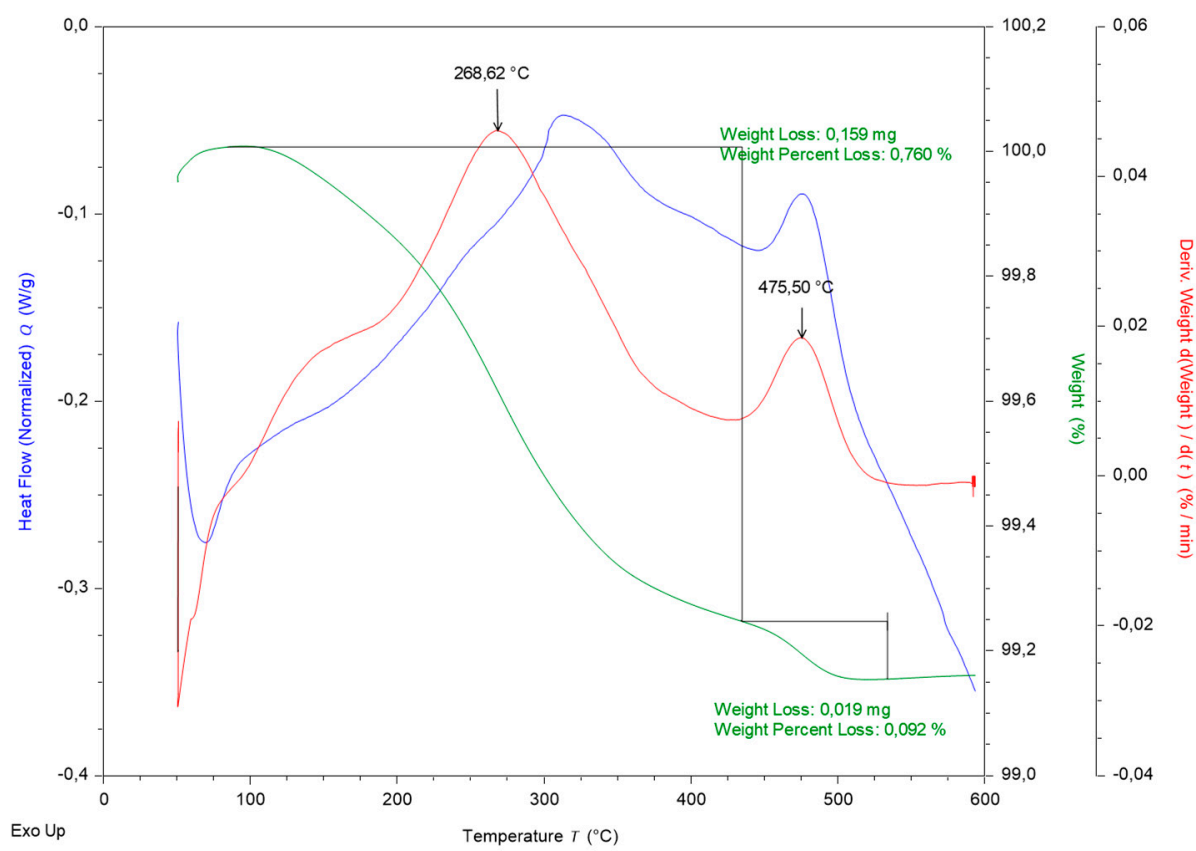

Figure 5. Fire clay DTA/TG curves.

As we can from Figure 4, the fire clay is composed of four basic components that are stable up to a temperature of $500{ }^{\circ} \mathrm{C}$, which is the maximum temperature reached in the reactor. The weight loss (green curve in Figure 5) is probably caused by leakage of free water trapped in the pore.

According to the chemical composition of the product it belongs to the category of fire clay materials. The phase composition fully corresponds to the chemical composition. The material contains residual quartz, which is customary for a given system. It can be assumed that this phase will remain in the product for the life of the product. The reversible phase transformation of $\alpha$ and $\beta$ form of cristobalite in the temperature range of $200{ }^{\circ} \mathrm{C}$ up to $270{ }^{\circ} \mathrm{C}$ can occur in the material. The present phases in the material are typical for refractory ceramic systems and there should be resistance against the temperature that is reached during microwave heating. Figure 5 confirms weight loss at $0.85 \mathrm{wt} \%$. The loss is generated while the material is heated to a temperature of approximately $500{ }^{\circ} \mathrm{C}$. Slight weight loss is related to the probable loss of adsorbed water.

The results of the sample cooling are in Figure 6. A final temperature of around $100{ }^{\circ} \mathrm{C}$ was chosen because it is comparable to the operating temperature of infra-panels. We can see that the cooling time of the sample from the initial temperature of about $300{ }^{\circ} \mathrm{C}$ to the final $100{ }^{\circ} \mathrm{C}$ was about 30 minutes. Such material heats up relatively quickly, but also quickly cools. 


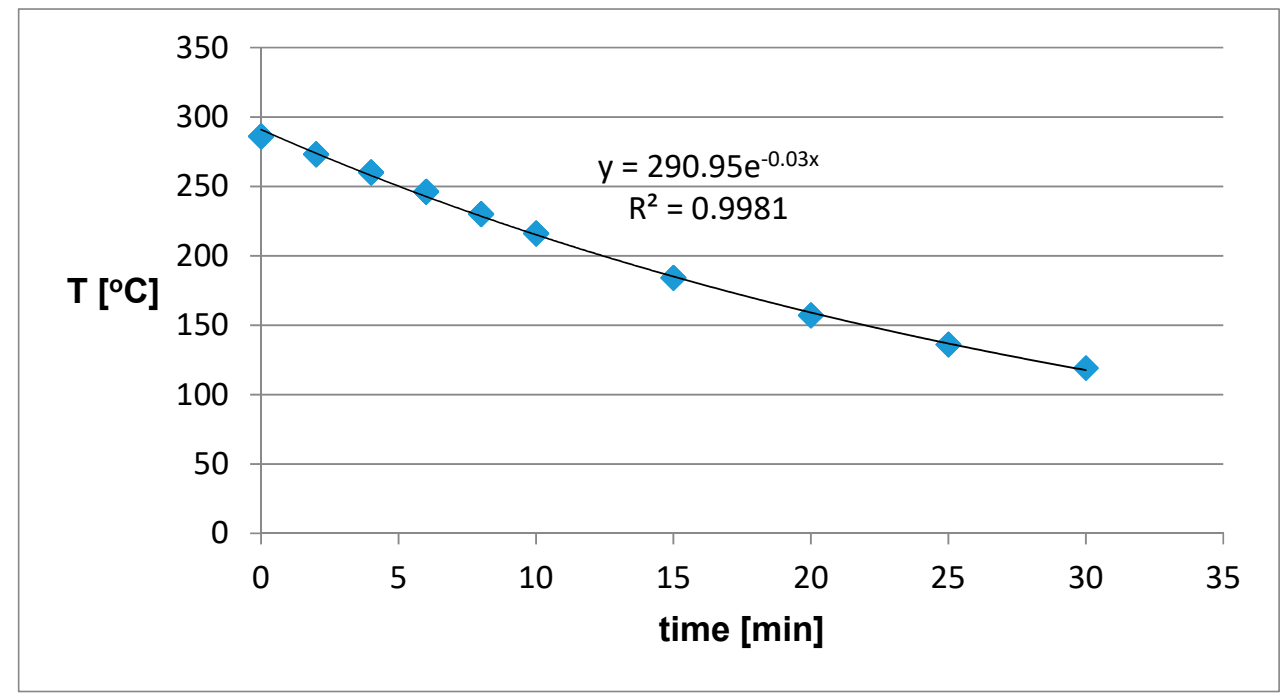

Figure 6. Fire clay sample cooling curve.

If metal mesh was pressed into this material (Figure 7), the initial sample temperature increased by about $150{ }^{\circ} \mathrm{C}$, while the cooling time remained the same because the thermal parameters of the sample material remained unchanged. This increase in the initial temperature (the final temperature during sample heating) can be attributed to the generation of heat in the metal network, in which the high-frequency field induces strong currents that serve as internal heat sources. This also increases the radiation component of electromagnetic energy calculated from the Stefan-Boltzmann law for an absolute black body approximately 2.5 times.

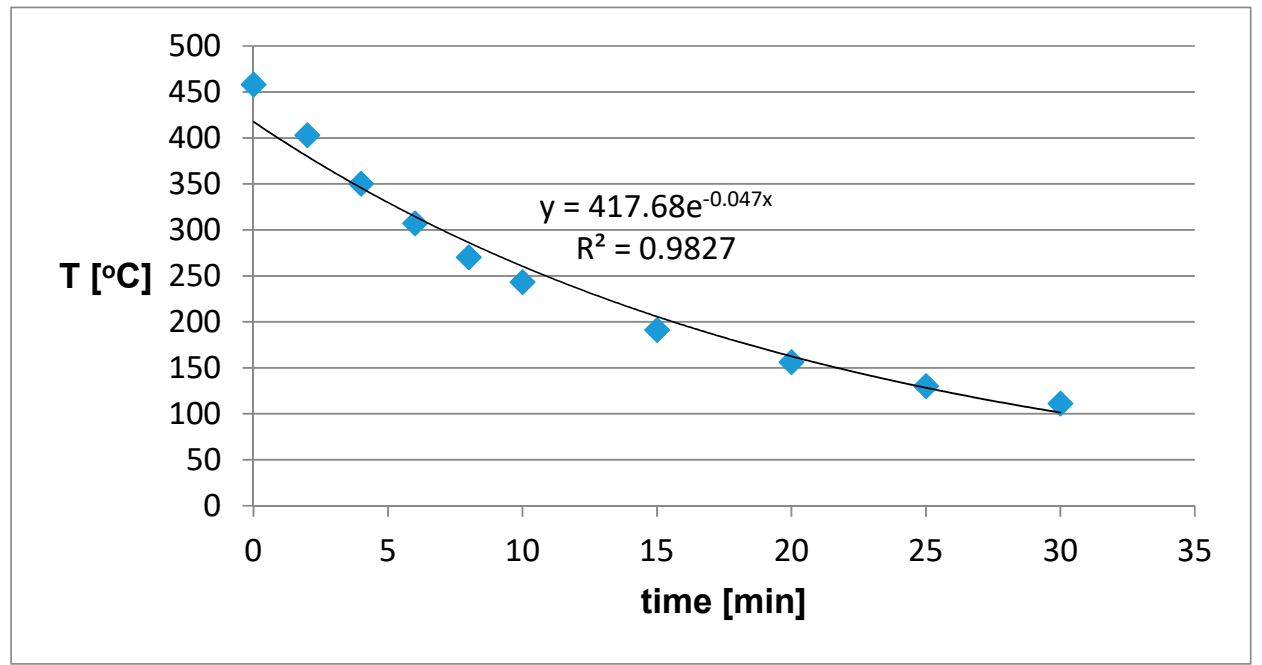

Figure 7. Fire clay sample cooling curve (sample with metal netting).

\subsection{Concrete}

Refractory concrete represented the second group of materials. Refractory concrete, as a mixture of refractory stone and binder, used after the addition of water or other liquid, is mainly processed by casting. The hydraulic bond is formed at ambient temperature.

The chemical composition is presented in Table 3, phase composition in Figure 8 and DTA/TG curves are shown in Figure 9. Mullite, quartz, cristobalite, and corundum are represented in the material. The final phase composition of concrete material is similar to the previous type of material; the difference is in the method of preparation. While the fire clay material is prepared from the clay constituent binder, the concrete material is prepared from a non-plastic raw material, where cement 
plays the role of the binder. Cement introduces a higher proportion of $\mathrm{CaO}$ in the sample than in the previous sample. Stability of the phases present in material can also be expected. The concrete and fire clay samples also have a mutual form in terms of the DTA/TG curve. The measured weight loss is $0.794 \mathrm{wt} \%$ and the pore content is $2.45 \%$.

Table 3. Chemical composition of concrete sample.

\begin{tabular}{cccccccccccc}
\hline Component & $\mathrm{Al}_{2} \mathrm{O}_{3}$ & $\mathrm{SiO}_{2}$ & $\mathrm{P}_{2} \mathrm{O}_{5}$ & $\mathrm{Na}_{2} \mathrm{O}$ & $\mathrm{K}_{2} \mathrm{O}$ & $\mathrm{CaO}$ & $\mathrm{TiO}_{2}$ & $\mathrm{Cr}_{2} \mathrm{O}_{3}$ & $\mathrm{MnO}$ & $\mathrm{Fe}_{2} \mathrm{O}_{3}$ & $\mathrm{LOI}$ \\
\hline Result (wt\%) & 34.3 & 55.1 & 0.73 & 0.63 & 0.88 & 4.06 & 1.51 & 0.12 & 0.27 & 1.51 & 0.89 \\
\hline
\end{tabular}

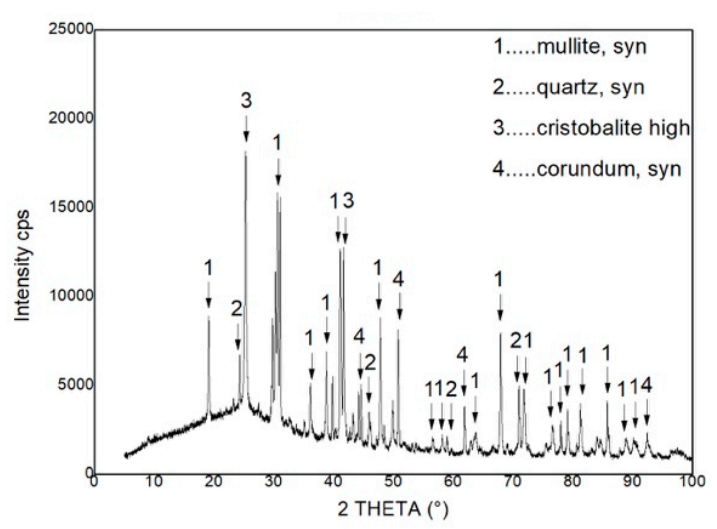

Figure 8. Concrete XRD pattern.

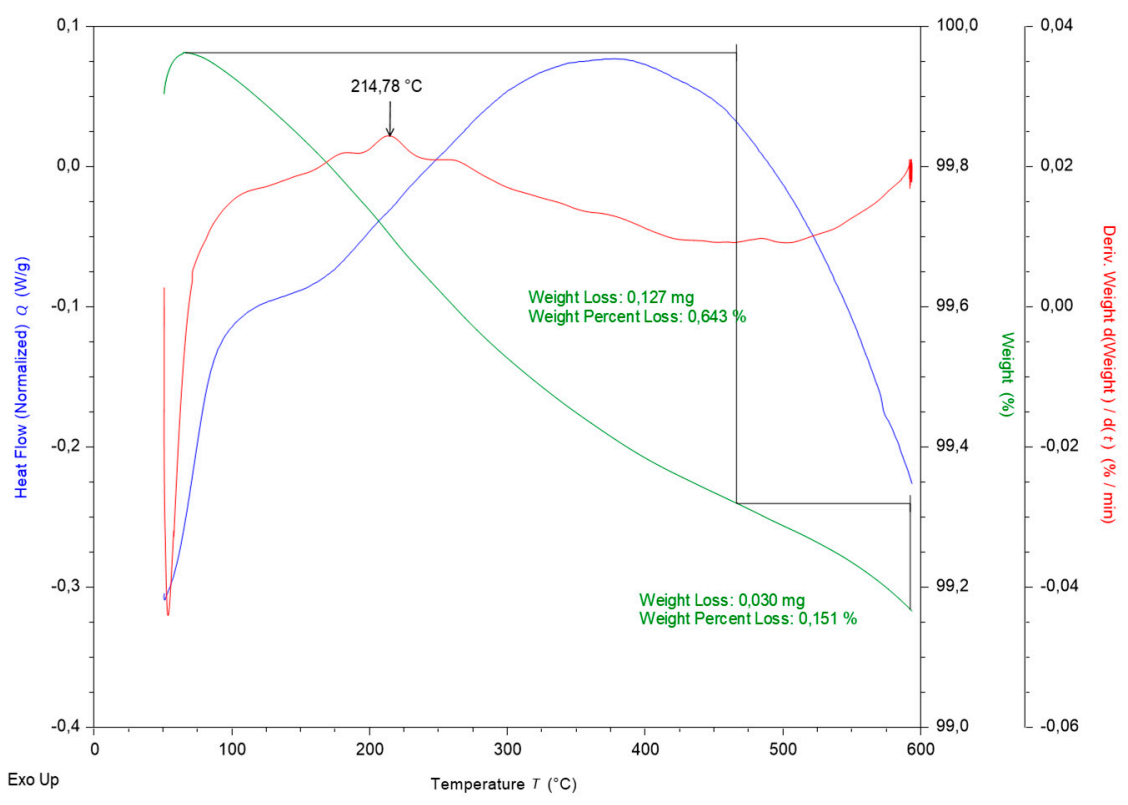

Figure 9. Concrete DTA/TG curves.

Concrete DTA/TG curves are in Figure 9 and present continual decrease of water content.

Figures 10 and 11 represent concrete sample cooling curves without metal netting (Figure 10) and with metal netting (Figure 11). 


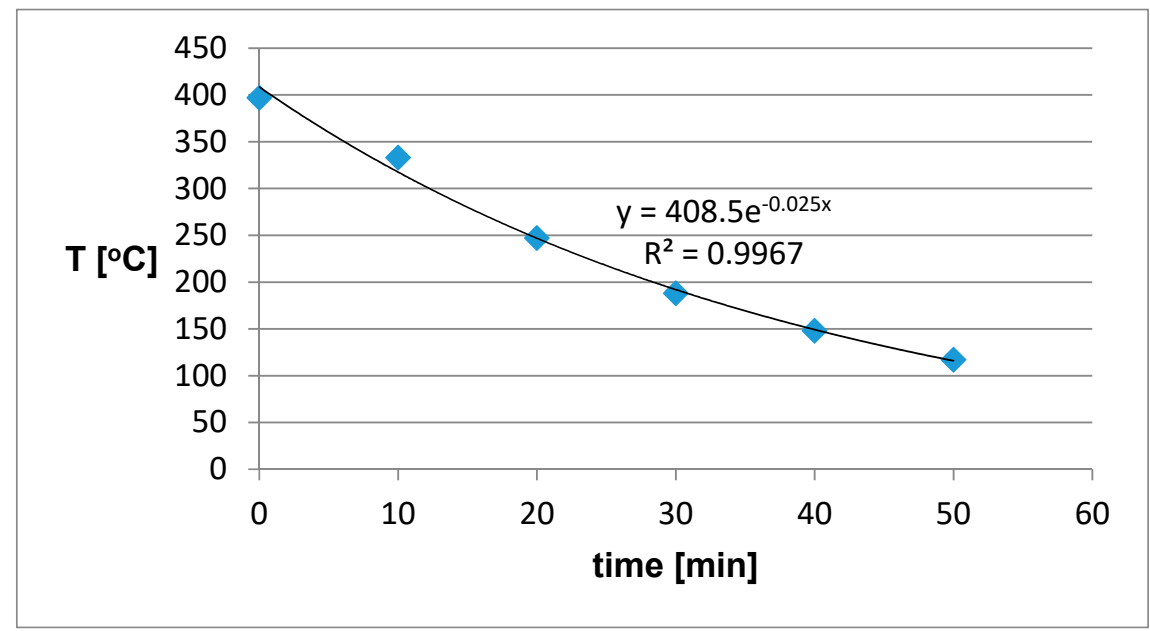

Figure 10. Concrete sample cooling curve (sample without metal netting).

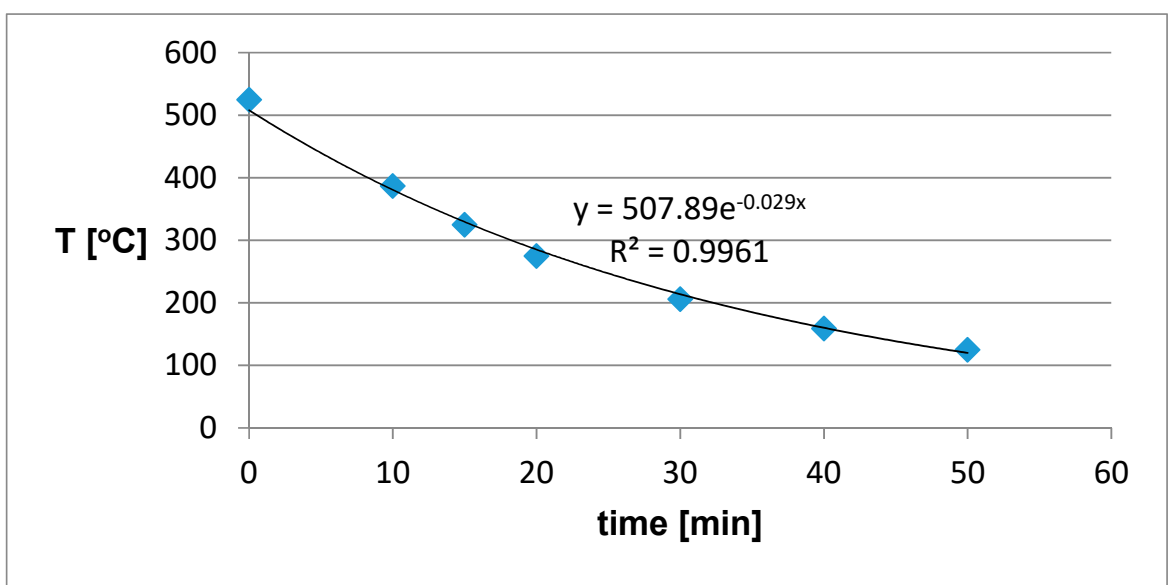

Figure 11. Concrete sample cooling curve (sample with metal netting).

We can see that this material has a higher storage capacity (lower diffusivity). The specific heat capacity is comparable to fire clay, but the thermal conductivity is higher, which is reflected by the lowest porosity. It is true that the phases contained in the material promise its long life.

A higher initial temperature was reached, but the time to reach the final temperature $\left(100{ }^{\circ} \mathrm{C}\right)$ took 20 minutes longer, which makes this material more suitable than fire clay from the previous experiment. When we pressed the metal mesh into this material (Figure 11), the initial temperature increased to almost $525^{\circ} \mathrm{C}$ and the sample cooling time was again 50 minutes. This increase in the initial temperature can again be attributed to the generation of heat in the metal mesh.

\subsection{Bauxite}

The third group of materials under investigation was bauxite mixed with water glass. Bauxite with a grain size $<160 \mu \mathrm{m}$ was mixed with water glass according to the following recipe: $800 \mathrm{~g}$ bauxite + $180 \mathrm{ml}$ water glass.

Water glass had the following composition:

- $\quad$ silicate module 2

- $\quad$ chemical composition: $28.51 \mathrm{wt} \% \mathrm{SiO}_{2} ; 9.07 \mathrm{wt} \% \mathrm{Na}_{2} \mathrm{O}$.

The chemical composition is presented in Table 4. Phase composition in Figure 12 and DTA/TG curves of bauxite are shown in Figure 13. 
Table 4. Chemical composition of bauxite sample.

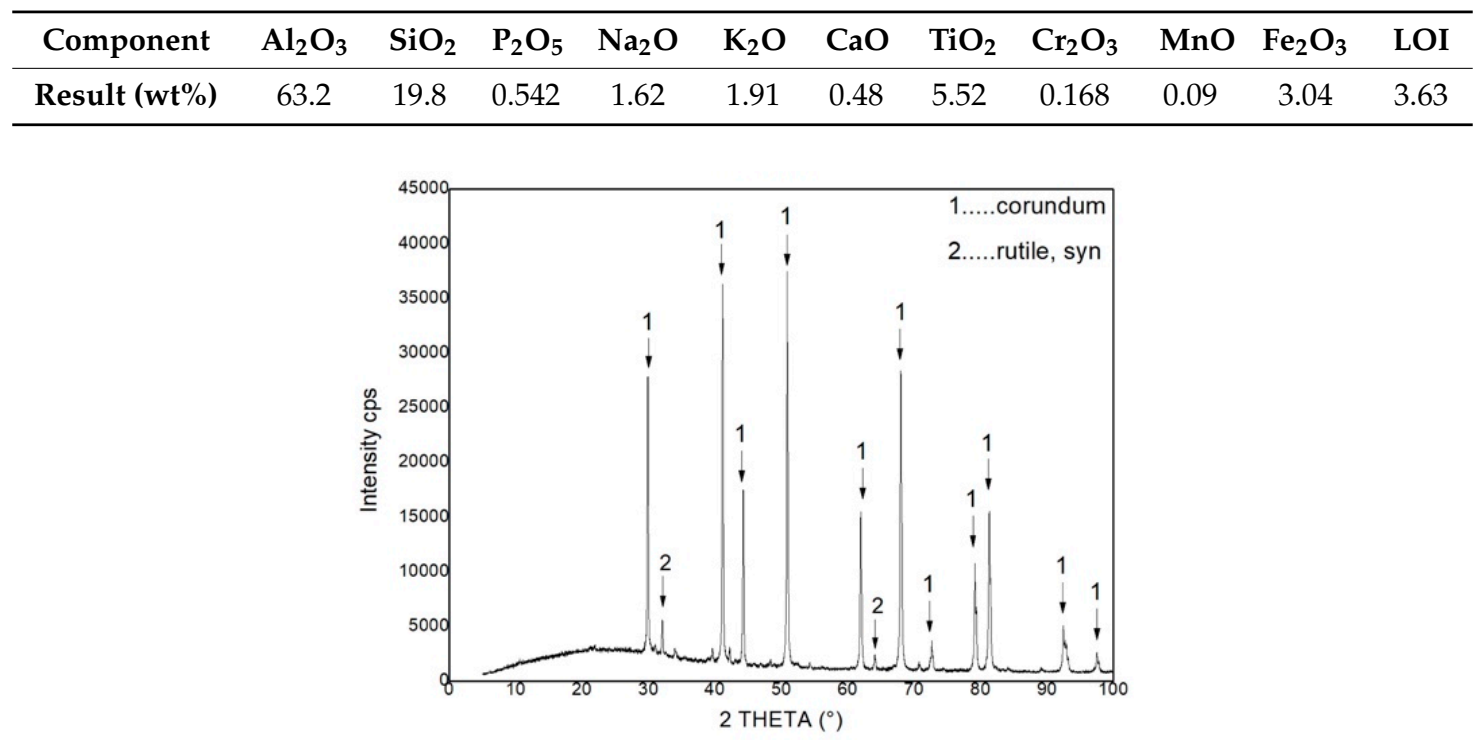

Figure 12. Bauxite XRD pattern.

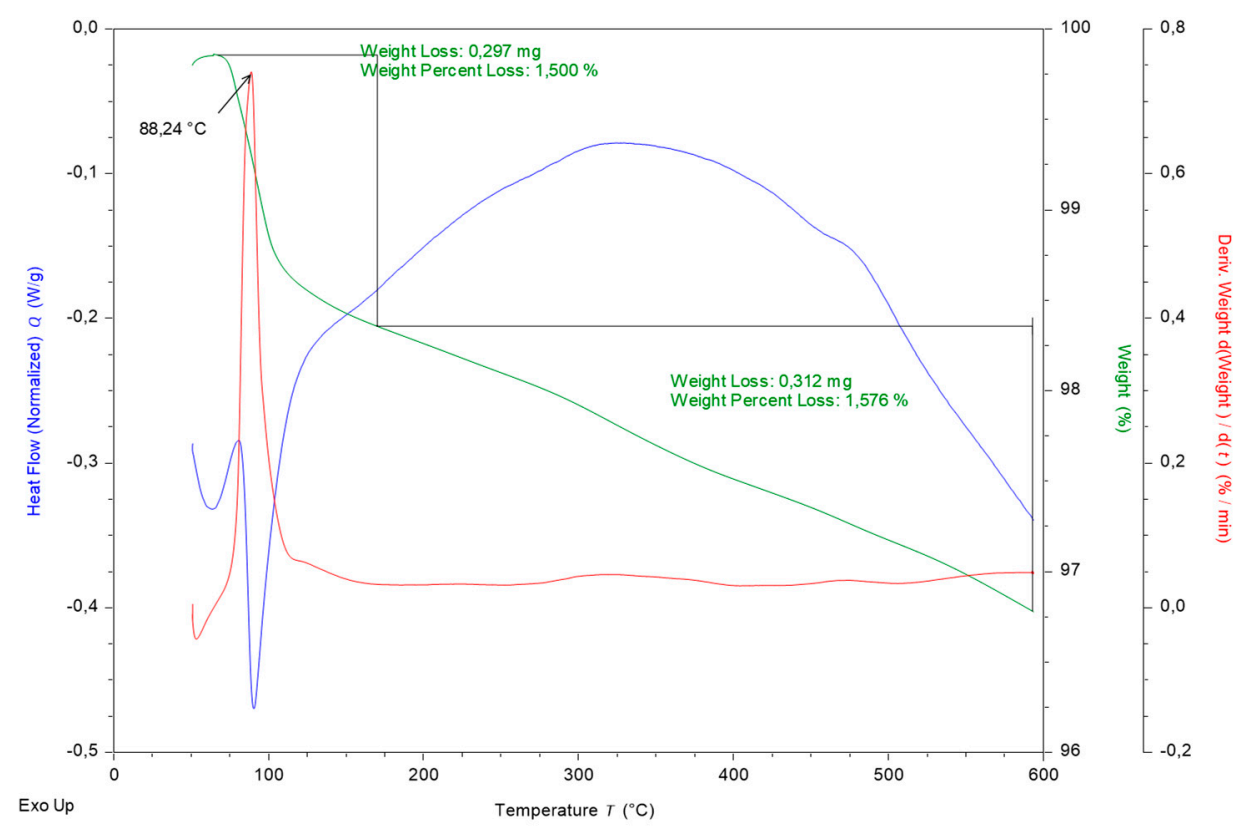

Figure 13. Bauxite DTA/TG curves.

Bauxite materials are among the high-clay materials. Aluminium oxide content above $63 \mathrm{wt} \%$ demonstrates this fact. The resulting phase composition of the material is corundum and rutile. The content of $\mathrm{SiO}_{2}$ was not confirmed by X-ray diffraction, which is amorphous in nature and the phase cannot be determined for $X$-ray diffraction. The material shows the highest weight loss, up to $3.076 \%$ according to the green TG curve. Again, weight loss is related to water loss. It is interesting that bauxite, as the material with the highest porosity (19\%), also showed the greatest weight change. It is true that the phases contained in the material promise its long life.

The cooling curve presented in Figure 14 has an exponential character as in the previous cases, but the initial temperature is higher than for the concrete. The cooling time is comparable to concrete but the initial cooling temperature is about $100{ }^{\circ} \mathrm{C}$ higher than that of refractory concrete, which is probably due to the increased number of water glass ions, which are also probably responsible for the highest value of thermal conductivity. 


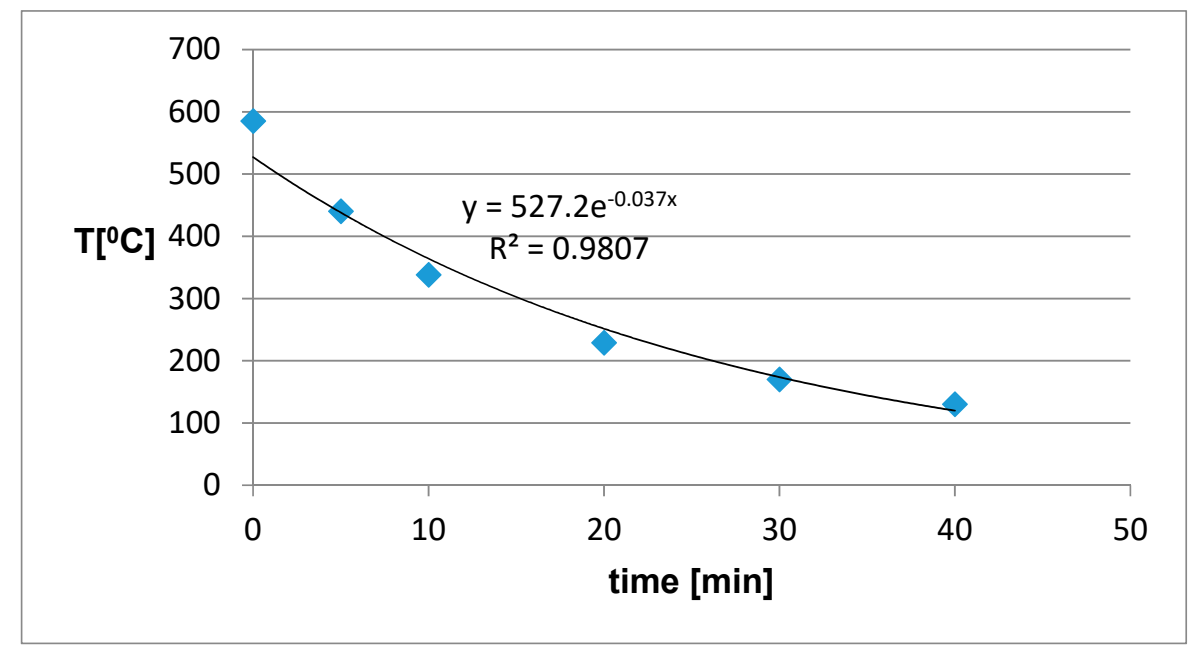

Figure 14. Cooling curve of bauxite with water glass.

We can state that the selected three materials exhibit excellent conversion properties and stability at repeated heating. The concrete and the bauxite with water glass are best suited.

Microwaves are currently used as sources of relatively high energy, in addition to heating food, mainly in technological processes [28-30]. In this section we present the application of microwaves to selected ceramic materials in order to obtain an efficient and cheap source of heating for living and utility areas.

In order to test the relevant material in a real heating body, we designed a microwave reactor according to the following specification (Figure 15). Electromagnetic radiation 2 radiated from the microwave source 1 is absorbed in the described composite ceramic materials 4 , which contains both bound and free water, suitable ions and, in addition, the metal netting. Losses by bound water releasing are minimal. Microwaves converted to heat 5 generated in the ceramics are transferred by contact to the heated space over a metal wall. Owing to its relatively high specific electric conductivity $(\mathrm{Cu})$ the metal surface functions as a shield against the electromagnetic waves, preventing their penetration into the heated space. The walls of the reactor, just like the ceramic material, are covered in the colour black 6 .

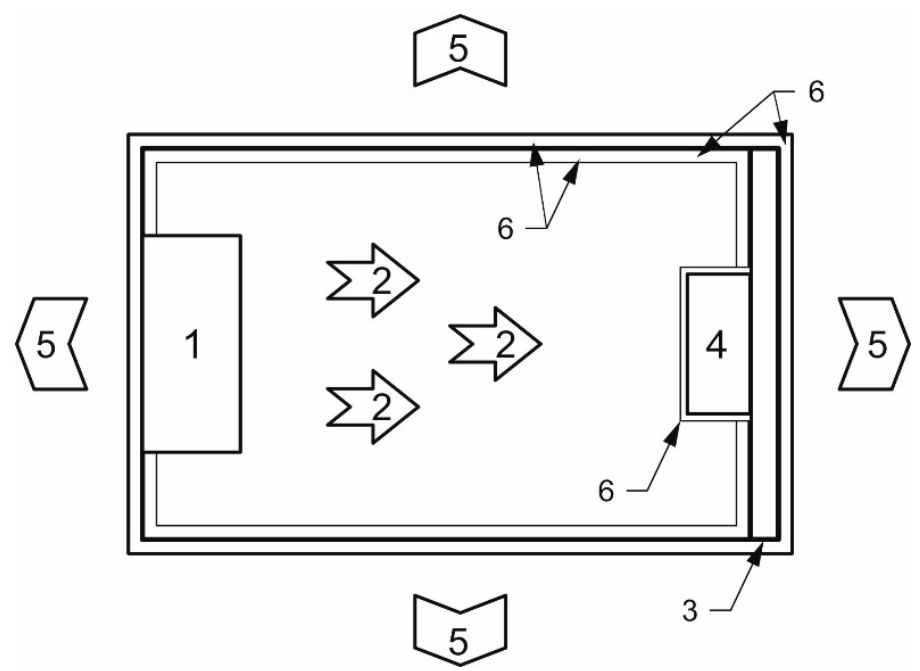

Figure 15. Diagram of the reactor: 1-magnetron, 2-microwave radiation, 3-metallic shield, 4-composite brick, 5-radiated heat, 6-black colour.

The described reactor was placed in a warm-padded house in a room of the volume of $46.5 \mathrm{~m}^{3}$. The consumed electrical input of overnight heating equalled $2.29 \mathrm{kWh}$ and the room was heated up 
from $15{ }^{\circ} \mathrm{C}$ to $22{ }^{\circ} \mathrm{C}$, which yielded-in conversion to cubic metres of the heated space- the value of $0.05 \mathrm{kWh} . \mathrm{m}^{-3}$. The measured power input values for large bricks without metal netting placed in the reactor are shown in Table 5.

Table 5. Material versus converted energy per room volume (without metallic netting).

\begin{tabular}{cc}
\hline Material & Electric energy per volume $\left[\mathbf{k W h} \cdot \mathbf{m}^{-3}\right]$ \\
\hline Fire clay & 0.05 \\
Concrete & 0.01 \\
Bauxite + water glass & 0.02 \\
\hline
\end{tabular}

We also studied the effect of absorbed heat in the walls and props in the heated room on its thermal comfort. The results are shown in Figure 16 and show the electrical work $\mathrm{A}^{22}$ in $\mathrm{kWh} . \mathrm{m}^{-3}$ required to maintain the temperature of $22{ }^{\circ} \mathrm{C}$ in the room under observation after heating to this temperature, depending on the number of days. The room was without direct ventilation and human presence. We can see that the required electrical input decreases, suggesting that less electrical energy is required to maintain thermal comfort $\left(22^{\circ} \mathrm{C}\right)$, or in other words, the walls and furniture also contributed to the room heating.

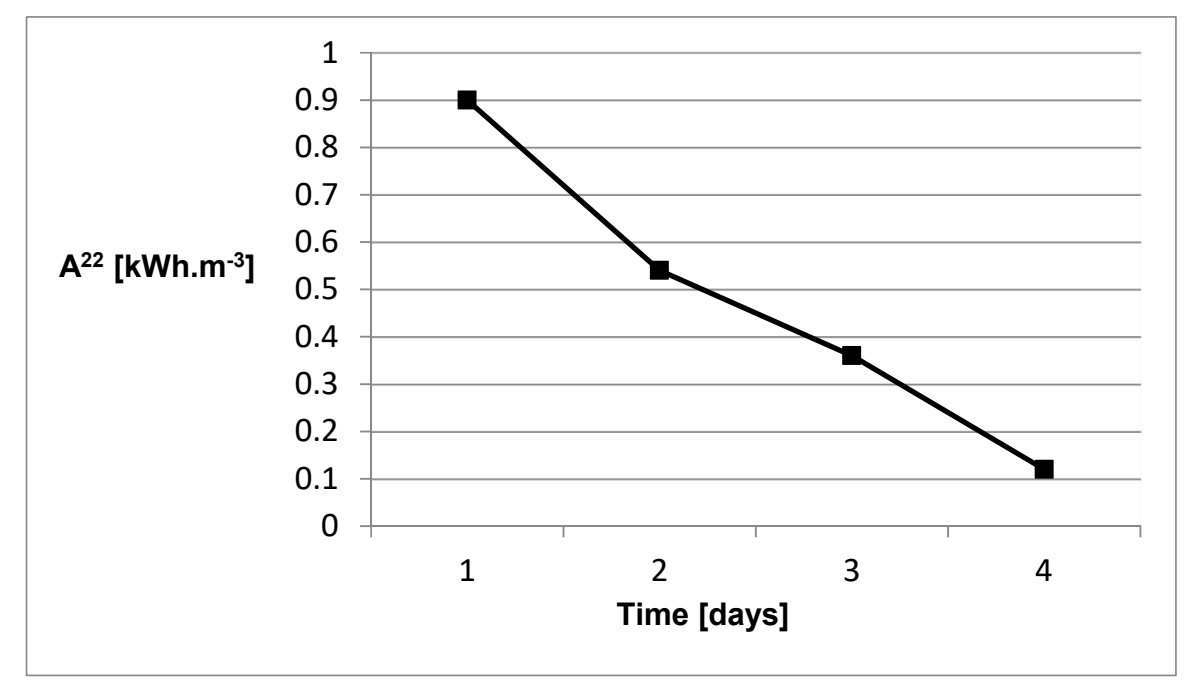

Figure 16. Dependence of electric work $\mathrm{A}^{22}$ on time.

The practical use of microwave devices is their safety [31-33]. The presented microwave reactor has been thoroughly tested for microwaves leakage. Since the whole reactor is all-metal, which prevents the leakage of microwaves, there is no risk of leakage into the heated space and a potential threat to human health.

From presented the data, we can see that the reactor represents a highly economical and safe heating of residential and utility spaces.

\section{Conclusions}

On the basis of a theoretical and experimental analysis of heat generation in a real dielectric medium we found and experimentally checked materials appropriate for conversion of microwaves to heating. We obtained results of fire clay bricks, concrete, and bauxite with water glass. These materials are characterised by the presence of water, both bound and free. On the other hand, the presence of ions in such structures enhances the heat generation. All these positive findings were supported by measurements of thermal parameters of materials under investigation, such as specific heat capacity, thermal conductivity, diffusivity, structure description, and corresponding cooling curves. In the future, 
it would be useful to explore other ceramic-based materials filled with different ions, which would increase thermal conductivity while reducing diffusivity.

We have discovered a very positive influence of pressed steel netting on the heat generation in described ceramics. All these aspects significantly contribute to the efficient transformation of microwave radiation to heat, which is then radiated by contact with the space over the metal wall that prevents the penetration of microwave radiation into the residential premises. In a newly developed and patented reactor we have tested real heating in the rooms.

On the basis of the presented results, we can conclude that the described solution of ecological, safe, and cheap heating of living spaces represents an effective step to increasing energy sustainability.

\section{Patents}

The research results in the Czech patent [31].

Author Contributions: Main roles of the authors are as follows, conceptualization, P.K., and J.V.; methodology, P.K.; software, Z.K.J., J.D., R.F., I.R.; validation, P.K., J.V., H.Š.; formal analysis, I.R.; investigation, P.K.; resources, P.K., J.V., H.Š., Z.K.J.; data curation, P.K.; writing—original draft preparation, P.K., Z.K.J.; writing—review and editing, P.K., Z.K.J.; visualization, J.D., R.F., I.R.; supervision, P.K.; project administration, P.K.; funding acquisition, J.V., H.S. All authors have read and agreed to the published version of the manuscript.

Funding: This research received no external funding.

Acknowledgments: This work was supported by Ministry of Education, Youth and Sports, Czech Republic, in the framework of the projects SP2019/17 and SP2019/62 and SP 2019/43. This work was supported by Ministry of Education, Science, Research and Sport of the Slovak Republic in the framework of the project VEGA 1/0717/19, and by the Ministry of Education, Youth and Sports, Czech Republic, in the framework of the projects SP2019/17, SP2019/62, SP 2019/43, and by the EU Regional Development Fund within the Operational Programme Research, Development and Education, under the aegis of the Ministry of Education, Youth and Sports of the Czech Republic; Project number CZ.02.1.01/0.0/0.0/17_049/0008426.

Conflicts of Interest: The authors declare no conflict of interest.

\section{References}

1. Řeháček, J.; Janouš, A.; Kučera, P.; Šafránek, J. Thermal Technical and Energy Characteristics of Buildings, 1st ed.; Grada: Praha, Czech Republic, 2002; p. 138.

2. Karlík, R. Tepelné Čerpadlo Pro Váš Dům, 1st ed.; Grada: Praha, Czech Republic, 2009; p. 112.

3. Halahyja, M.; Valášek, J. Solárna Energia A Jej Využitie, 1st ed.; Alfa: Bratislava, Slovak Republic, 1983; p. 296.

4. Lu, J.; Zhao, X. Electrorheological properties of a polyaniline-montmorillonite clay nanocomposite suspension. J. Mater. Chem. 2002, 12, 2603-2605. [CrossRef]

5. Lerf, A.; Čapková, P. Encyclopedia of Nanoscience and Nanotechnology, 2nd ed.; American Scientific Publishers: Stevenson Ranch, CA, USA, 2004; pp. 639-694.

6. Zheng, H.; Feng, X.; Zhou, L.; Ye, Y.; Chen, J. Intercalated polyaniline-kaolinite nanocomposite prepared via in situ mechanochemical synthesis. J. Appl. Polym. Sci. 2016, 133. [CrossRef]

7. Lagaly, G.; Ogawa, M.; Dékány, I. Clay Mineral—Organic Interactions. In Handbook of Clay Science, 1st ed.; Bergaya, F., Lagaly, G., Eds.; Elsevier: Amsterdam, The Netherlands, 2013; Volume 5, pp. 435-505.

8. Motz, H.; Geisler, J. Products of Steel Slags. An Opportunity to Save Natural Resources. In Waste Materials in Construction, 1st ed.; Woolley, G.R., Goumans, J.J.M., Wainwright, P.J., Eds.; PERGAMON: Kidlington, UK, 2000; Volume 1, pp. 207-221.

9. Kurdowski, W. Chemia Cementu, 1st ed.; Wydawnictwo Naukove PWN: Warszawa, Poland, 1991; p. 228.

10. Kourounis, S.; Tsivilis, S.; Tsakiridis, P.E.; Papadimitriou, G.D.; Tsibouki, Z. Properties and hydration of blended cements with steelmaking slag. In Cement and Concrete Research, 1st ed.; Scrivener, K., Roy, D.M., Eds.; Elsevier: Amsterdam, The Netherlands, 2007; Volume 37, pp. 815-822.

11. Roy, D.M. Alkali-activated cements Opportunities and challenges. In Cement and Concrete Research, 1st ed.; Silsbee, M., Ed.; Elsevier: Amsterdam, The Netherlands, 1999; Volume 29, pp. 249-254.

12. Shi, C.; Krivenko, P.V.; Roy, D.M. Alkali-Activated Cement and Concretes, 1st ed.; Taylor \& Francis: London, UK, 2006; p. 392.

13. Lee, A.R. Blast Furnace and Steel Slag, 1st ed.; Edward Arnold: London, UK, 1974; pp. 62-63. 
14. Štefko, J.; Bednár, J. Wood based building envelope regarding air tightness. Key Eng. Mater. 2016, 688, 160-166. [CrossRef]

15. Krišt'ák, L'.; Igaz, R.; Ružiak, I. Applying the EDPS Method to the Research into Thermophysical Properties of Solid Wood of Coniferous Trees. Adv. Mater. Sci. Eng. 2019, 2019, 2303720. [CrossRef]

16. Sorrentino, R.; Bianchi, G. Microwave and RF Engineering, 1st ed.; Wiley: New York, NY, USA, 2010; p. 912.

17. Skolnik, M.I. Introduction to Radar Systems, 3rd ed.; McGraw-Hill Education: New York, NY, USA, 2002; p. 784.

18. Sisodia, M.L. Microwaves: Introduction to Circuits, Devices and Antennas, 1st ed.; New Age International: New Delhi, India, 2007.

19. Krempaský, J. Fyzika: Příručka Pre Vysoké Školy Technické, 1st ed.; Alfa: Praha, Czech Republic, 1982; p. 751.

20. Ford, W.F. The Effect of Heat on Ceramics, 1st ed.; Mclaren and Sons Ltd.: London, UK, 1967; pp. 95-96.

21. Matthes, S. Mineralogie: Eine Einführung in Die Spezielle Mineralogie, Petrologie und Lagerstättenkunde, 6th ed.; Springer-Verlag: Berlin/Heidelberg, Germany, 2001; p. 507.

22. Hinz, W. Silikate, 1st ed.; VEB Verlag Für Bauwesen: Berlin, Germany, 1970; pp. 210-211.

23. Davidovits, J. Geopolymer Chemistry \& Application, 4th ed.; Institut Geopolymere: Saint Quentin, France, 2008; p. 620.

24. Cosgun, S.; Semerci, N. Combined and individual applications of ozonation and microwave treatment for waste activated sludge solubilization and nutrient release. J. Environ. Manag. 2019, 241, 76-83. [CrossRef] [PubMed]

25. Ghayur, A.; Verheyen, T.V.; Meuleman, E. Biological and chemical treatment technologies for waste amines from $\mathrm{CO}_{2}$ capture plants. J. Environ. Manag. 2019, 241, 514-524. [CrossRef] [PubMed]

26. Hesas, R.H.; Baei, M.S.; Rostami, H.; Gardy, J.; Hassanpour, A. An investigation on the capability of magnetically separable $\mathrm{Fe}_{3} \mathrm{O}_{4}$ /mordenite zeolite for refinery oily wastewater purification. J. Environ. Manag. 2019, 241, 525-534. [CrossRef] [PubMed]

27. Koštial, P.; Špička, I.; Jančíková, Z.; Rusnák, V. On the solid state heat transport phenomena measurement. Mater. Und Werkst. 2015, 46, 1110-1118.

28. Bu, Q.; Chen, K.; Xie, W.; Liu, Y.; Cao, M.; Kong, X.; Chu, Q.; Mao, H. Hydrocarbon rich bio-oil production, thermal behavior analysis and kinetic study of microwave-assisted co-pyrolysis of microwave-torrefied lignin with low density polyethylene. Bioresour. Technol. 2019, 291, 121860. [CrossRef] [PubMed]

29. Azni, A.A.; Ghani, W.A.W.A.K.; Idris, A.; Ja'afar, M.K.Z.; Salleh, M.A.M.; Ishak, N.S. Microwave-assisted pyrolysis of EFB-derived biochar as potential renewable solid fuel for power generation: Biochar versus sub-bituminous coal. Renew. Energy 2019, 142, 123-129. [CrossRef]

30. Liu, C.; Grimi, N.; Lebovka, N.; Vorobiev, E. Convective air, microwave, and combined drying of potato pre-treated by pulsed electric fields. Dry. Technol. 2019, 37, 1704-1713. [CrossRef]

31. Koštial, P.; Koštialová Jančíková, Z.; Vlček, J. A Method of Heating A Space by Converting Microwave to Heat and An Apparatus for Carrying Out the Method; Technical University of Ostrava: Ostrava, Czech Republic, 2019. (In Czech)

32. Calabro, E. Introduction to the Special Issue "Electromagnetic Waves Pollution". Sustainability 2018, 10, 3326. [CrossRef]

33. Pierdicca, R.; Paolanti, M.; Bacchiani, R.; de Leo, R.; Bisceglia, B.; Frontoni, E. Accurate Modeling of the Microwave Treatment of Works of Art. Sustainability 2019, 11, 1606. [CrossRef]

(C) 2019 by the authors. Licensee MDPI, Basel, Switzerland. This article is an open access article distributed under the terms and conditions of the Creative Commons Attribution (CC BY) license (http://creativecommons.org/licenses/by/4.0/). 